\title{
Fabrication and Characterization of Titanium Dioxide-Cellulose Composite and Its Urea Biosensing Behavior
}

\author{
Kafy Abdullahil, Mohammad Maniruzzaman, \\ Byung-Woo Kang and Jaehwan Kim* \\ Center for EAPap Actuator, Department of Mechanical Engineering, Inha University, \\ 253 Yonghyun-Dong, Nam-Ku, Incheon 402-751, Korea
}

(Received January 15, 2015; accepted April 30, 2015)

Key words: cellulose, titanium dioxide, composite, urea, biosensor

In this paper, the fabrication of a titanium dioxide $\left(\mathrm{TiO}_{2}\right)$-cellulose composite and its urea biosensing behavior are reported. $\mathrm{TiO}_{2}$ nanoparticles were blended with the cellulose solution prepared by dissolving cotton pulp with a lithium chloride $/ N, N$ dimethylacetamide solvent, and a $\mathrm{TiO}_{2}$-cellulose composite was fabricated. The enzyme urease was immobilized into the composite by using a physical adsorption method. The developed urea biosensor is highly sensitive at urea concentrations lower than 10 $\mathrm{mM}$, whereas it maintains a linear response up to a urea concentration of $50 \mathrm{mM}$. The $\mathrm{TiO}_{2}$-cellulose composite is a potential candidate urea biosensor, which is inexpensive, flexible, and disposable.

\section{Introduction}

Polymer-metal oxide hybrid composites constitute an attractive new class of functional hybrid materials that show enhanced optical, thermal, and mechanical properties due to the synergistic effects resulting from the physical or chemical interactions between the organic and inorganic elements. ${ }^{(1)}$ Cellulose is the most abundant renewable biomaterial in the world, which can be regenerated or modified to produce numerous useful products. ${ }^{(2,3)}$ Recently, cellulose has been used for hybrid nanocomposites, which are advantageous in terms of flexibility, renewability, biodegradability, and biocompatibility. ${ }^{(4)}$ The renewability and biodegradability of cellulose are really essential behaviors for flexible electronics and biosensors because these ecofriendly behaviors can make devices disposable. On the other hand, titanium dioxide $\left(\mathrm{TiO}_{2}\right)$ is a wide-band-gap semiconducting material, which has recently attracted much interest owing to its chemical stability, electrical conductivity, photocatalytic activity, and photosensitivity. ${ }^{(8)} \mathrm{TiO}_{2}$ has been widely used for solar cells, photocatalysis,

${ }^{*}$ Corresponding author: e-mail: jaehwan@inha.ac.kr 
photoelectrochemical cells, chemical sensors, and electronic devices. ${ }^{(9,10)}$ Thus, it is a novel idea to make a composite of $\mathrm{TiO}_{2}$ and cellulose so as to offer the ecofriendly behaviors of cellulose in conjunction with the advanced electrical properties of $\mathrm{TiO}_{2}$.

The urea biosensor has received great interest owing to its considerable importance in agricultural and food chemistry, environment monitoring, and clinical purposes. ${ }^{(11)}$ There is a growing demand for low cost, highly sensitive, and real-time monitoring urea biosensors. Urea $\left[\left(\mathrm{NH}_{2}\right)_{2} \mathrm{CO}\right]$ is basically an organic compound of carbon, nitrogen, oxygen, and hydrogen, and is an end product of nitrogen waste originating from protein and amino acid catabolism in living organisms. The usual level of urea in serum is 3 to $7 \mathrm{mM}(15-40 \mathrm{mg} / \mathrm{dl})$, whereas when patients suffer renal insufficiency it can be in the range of 30 to $80 \mathrm{mM}(180-480 \mathrm{mg} / \mathrm{dl})$, and hemodialysis is necessary when its level crosses $180 \mathrm{mg} / \mathrm{dl}$. Beyond the low cost, highly sensitive, and real time monitoring behaviors, disposable and ecofriendly behaviors will be very beneficial for food and medical urea biosensors. Numerous polymers have been reported as matrices of sensors including a polypyrrole and polyion complex, polyaniline-poly( $n$-butyl methacrylate), polyurethane, poly(vinyl ferrocenium), and carboxylic poly(vinyl chloride). ${ }^{(12-16)}$ However, little attention has been given to cellulose-based composites for urea detection.

Here, we report a disposable urea biosensor made of a $\mathrm{TiO}_{2}$-cellulose composite (TCC). The TCC has many advantages for biosensors since it is flexible, ecofriendly, biodegradable, disposable, and highly sensitive. The fabrication of the TCC and a urea biosensor and its sensing behavior are presented.

\section{Materials and Methods}

\subsection{Materials}

The cotton pulp (MVE, DPW 4500) was purchased from Buckeye Technologies Co., USA. Lithium chloride ( $\mathrm{LiCl}$, extra pure) was purchased from Junsei Chemical, Japan. $N, N$-dimethylacetamide (DMAc) (anhydrous, 99.8\%), sodium dodecyl sulfate (SDS), titanium (IV) oxide [mixture of rutile and anatase, nanopowder, $<100 \mathrm{~nm}$ (BET), 99.5\% trace metal basis], and the enzyme urease (EC 3.5.1.5, type III from jack bean, 39290 units/g) were purchased from Sigma-Aldrich, USA. Urea [assay $\geq 98 \%$, chloride $(\mathrm{Cl}) \leq$ $20 \mathrm{ppm}$, iron $(\mathrm{Fe}) \leq 20 \mathrm{ppm}]$ was purchased from Samchun Chemical, Korea.

\subsection{Fabrication of $\mathrm{TiO}_{2}$-cellulose composite}

The fabrication of TCC has been reported elsewhere ${ }^{(17)}$ and this is a brief summary. First, cellulose was dissolved to form a solution. The cotton pulp was torn and dried in a heating oven at $100^{\circ} \mathrm{C}$. The pulp was mixed with $\mathrm{LiCl} /$ anhydrous DMAc proportionally to cotton pulp/LiCl/DMAc at $2 / 8 / 90$. The cellulose was dissolved in the solvent system by heating at $155^{\circ} \mathrm{C}$ with mechanical stirring followed by solvent exchange. ${ }^{(18)}$ Different amounts of $\mathrm{TiO}_{2}$ nanoparticles $\left(80,160\right.$, and $240 \mathrm{mg}$ ) annealed at $600{ }^{\circ} \mathrm{C}$ in a tube furnace as well as sodium dodecyl sulfate $(100 \mathrm{mg})$ were mixed with $15 \mathrm{ml}$ of anhydrous DMAc and sonicated in an ultrasonic bath for $1 \mathrm{~h}$ to obtain a homogeneous mixture. Sodium dodecyl sulfate was used as a dispersing agent and sonicated again for $1 \mathrm{~h}$. Then, these stock solutions of $\mathrm{TiO}_{2}$ were added to $50 \mathrm{~g}$ of $1.5 \mathrm{wt} \%$ cellulose solution prepared earlier to obtain 10, 20, and $30 \mathrm{wt} \% \mathrm{TiO}_{2}$-cellulose mixtures. These mixtures 
were mechanically stirred for $2 \mathrm{~h}$. The obtained mixtures were then spin-coated onto a glass substrate and cured with isopropyl alcohol and deionized water to obtain TCC. The wet TCC was dried at room temperature. Figure 1 shows the TCC fabrication process.

\subsection{Characterization of TCC}

The fabricated TCC was characterized by scanning electron microscopy (SEM, Hitachi S4300). X-ray diffraction (XRD) patterns were recorded with a thin-film $\mathrm{X}$-ray diffractometer using a $\mathrm{Cu} \mathrm{K} \alpha$ target at $40 \mathrm{kV}$ and $50 \mathrm{~mA}$, at a scanning rate of $0.015 \%$ min. Samples were mounted on a standard sample holder and analyzed using the microfocused, monochromated Al K (X-ray source with a spot size of $400 \mu \mathrm{m}$ ). The chemical elements presented in the samples were identified from the survey spectra. The survey scans started at $1400 \mathrm{eV}$ and ended at $0 \mathrm{eV}$ taking $1 \mathrm{eV}$ steps with a dwell time of $200 \mathrm{~ms}$.

\subsection{Enzyme immobilization for urea sensing}

The biologically active element mostly employed for detecting urea is urease, which catalyzes the hydrolysis of urea to ammonium and bicarbonate ions. The immobilization techniques available for urease include encapsulation and entrapment, covalent/ionic binding, physical adsorption, and cross-linking. Each of these processes has its own advantages and disadvantages such that one can choose an appropriate technique on

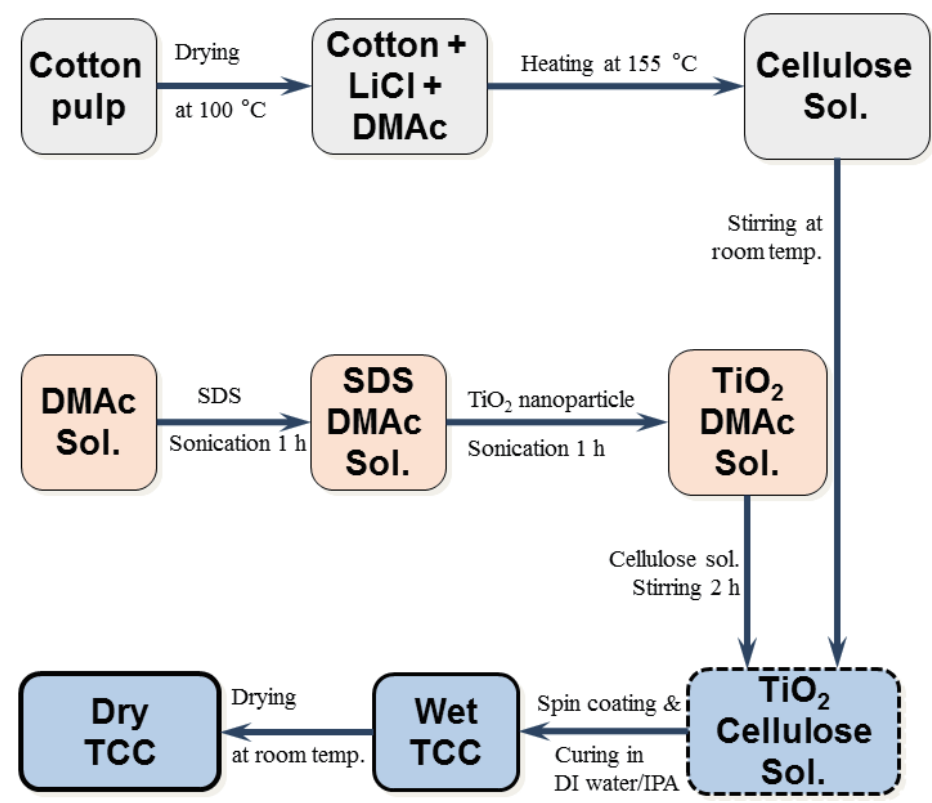

Fig. 1. (Color online) TCC fabrication process. 
the basis of the biosensor used. Urease was immobilized into the TCC by physical adsorption. A gold layer $\left(5 \times 5 \mathrm{~mm}^{2}\right)$ was sputtered on both sides of the TCC before urease immobilization. Firstly, urease solution was prepared by dissolving $0.2 \mathrm{mg}$ of urease per $\mathrm{ml}$ of $0.1 \mathrm{M}$ phosphate buffer solution (pH 7.2). Second, TCC samples were immersed in $\mathrm{pH}$ buffer and urease solutions for $16 \mathrm{~h}$ at room temperature $\left(25^{\circ} \mathrm{C}\right)$. The samples were then washed with deionized water and stored in the phosphate buffer solution ( $\mathrm{pH} 7$ ) until use.

\subsection{Urea sensing characterization}

The conductometric electrical behavior of the urease-immobilized TCC was measured to determine its enzyme activity. Figure 2 shows the test setup. To measure its electrical property, a test cell, which consists of a gold wire $(0.3 \mathrm{~mm} \phi, 5 \mathrm{~cm}$ length $)$ as a reference electrode and a urease-immobilized TCC $\left(7 \times 45 \mathrm{~mm}^{2}\right)$ as a working electrode, was constructed. The urea solution prepared in deionized (DI) water with varying concentration (1-20 mM) was used as an electrolyte. For this measurement, a dc potential from 0 to $2 \mathrm{~V}$ was applied to the TCC and the corresponding DC current was determined by employing a semiconductor parameter analyzer (HP4145B). We chose this voltage range for measurable current detection. For each sample, five sets of measurement were accomplished. The enzyme activity was measured at room temperature. The slope of the current vs potential $(I-V)$ curve $(\Delta I / \Delta V)$ was used as an indicator of the sensitivity of the urea biosensor. The sensitivity of the biosensor was then calculated using the following equation:

$$
\text { Sensitivity }=\frac{\left(\frac{\Delta I}{\Delta V}\right)_{x}-\left(\frac{\Delta I}{\Delta V}\right)_{0}}{\left(\frac{\Delta I}{\Delta V}\right)_{0}} .
$$

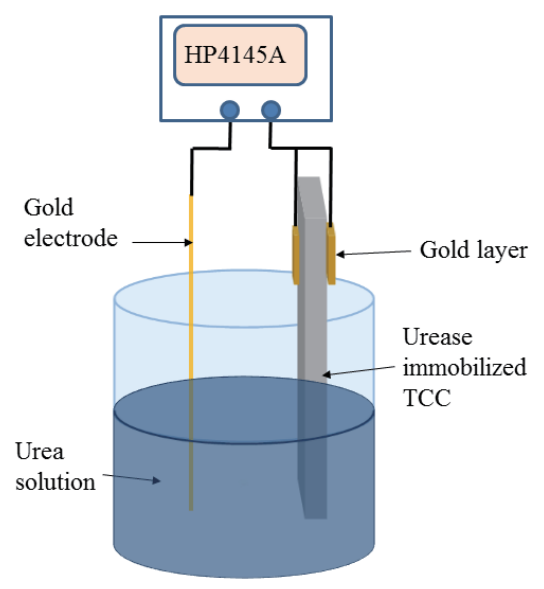

Fig. 2. (Color online) Schematic diagram of the TCC urea biosensor test. 
Here, $(\Delta I / \Delta V)_{x}$ is the slope of the $I-V$ curve at $x \mathrm{mM}$ urea, where $x=1-20 \mathrm{mM}$, and $(\Delta I /$ $\Delta V)_{0}$ is the slope of the $I-V$ curve at $0 \mathrm{mM}$ urea.

\section{Results and Discussion}

\subsection{Fabrication of TCC}

The fabricated TCC samples were tested by obtaining SEM images, XRD patterns, and thermogravimetric analysis (TGA) curves. Test results were almost the same as those reported previously, which indicate that the TCC was successfully fabricated. Figure 3(a) displays the surface SEM image of a TCC with $20 \mathrm{wt} \% \mathrm{TiO}_{2}$. Since $\mathrm{TiO}_{2}$ nanoparticles were blended with cellulose, they were uniformly distributed all over the surface of cellulose. Figure 3(b) shows the cross-sectional SEM image of the TCC, with the layered structure of cellulose covered with $\mathrm{TiO}_{2}$ nanoparticles. Figure 4 shows the XRD pattern of the TCC. The peak at $20.6^{\circ}$ shows the main peak of cellulose II. $\mathrm{TiO}_{2}$ peaks are shown at $25.4,27.5,36.2$, and $54.3^{\circ}$, which indicate anatase and rutile structures of $\mathrm{TiO}_{2}$.
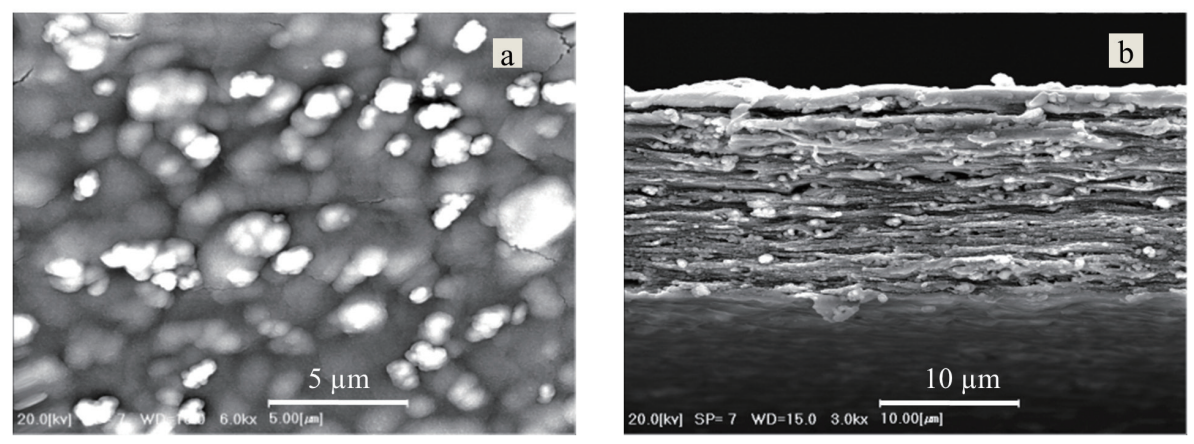

Fig. 3. SEM images of TCC with $20 \mathrm{wt} \%$ of $\mathrm{TiO}_{2}$ : (a) surface and (b) cross section.

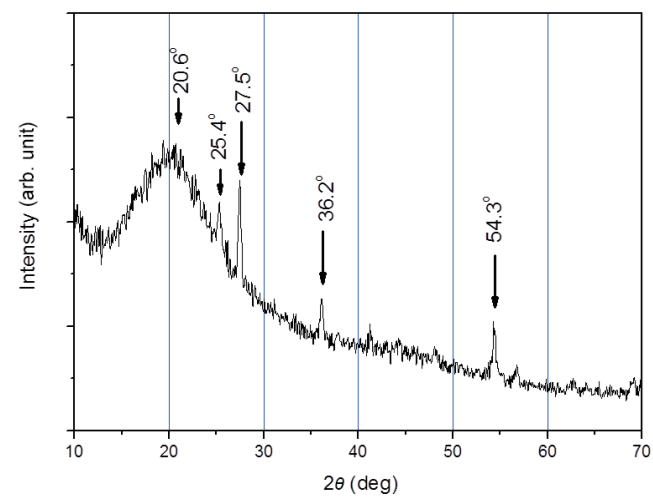

Fig. 4. XRD pattern of the fabricated $\mathrm{TCC}$ with $30 \mathrm{wt} \%$ of $\mathrm{TiO}_{2}$. 
Figure 5 shows TGA curves of the fabricated TCC with various weight percent values of $\mathrm{TiO}_{2}$. The TGA curve of the pristine cellulose is shown for comparison. Note that the thermal degradation temperature of the pristine cellulose is $340{ }^{\circ} \mathrm{C}$; however, by adding $\mathrm{TiO}_{2}$, the temperature of the TCC is decreased to $270{ }^{\circ} \mathrm{C}$. TGA traces of the TCC with 10,20 , and $30 \mathrm{wt} \% \mathrm{TiO}_{2}$ are found to be $37.5,46.4$, and $48.0 \%$, respectively. The traces of the TCC increase with increasing weight percent value of $\mathrm{TiO}_{2}$.

\subsection{Effect of $\mathrm{TiO}_{2}$ weight ratio}

$I-V$ characteristics of TCC samples prepared with different weight ratios of $\mathrm{TiO}_{2}$ were measured to analyze the effect of $\mathrm{TiO}_{2}$ weight ratio on the sensing behavior of the TCC urea sensor. The measurement was conducted using $10 \mathrm{mM}$ urea solution. Figure 6(a)

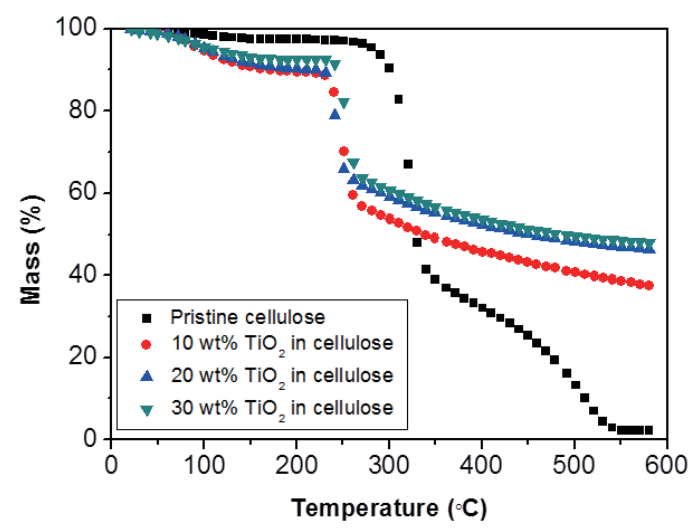

Fig. 5. (Color online) TGA curves of the TCC samples.

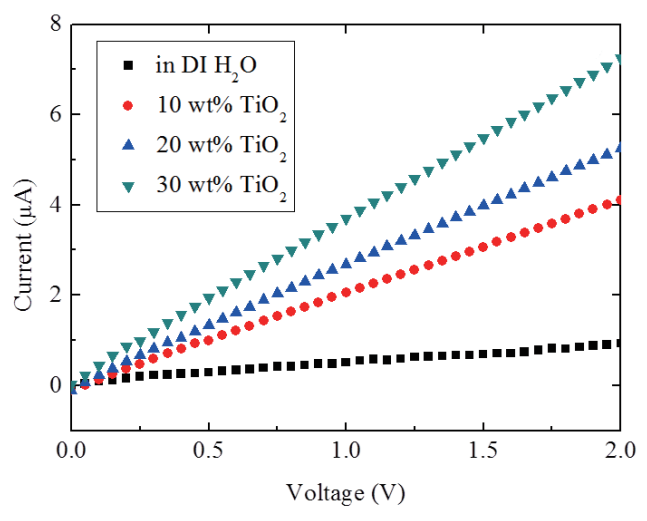

(a)

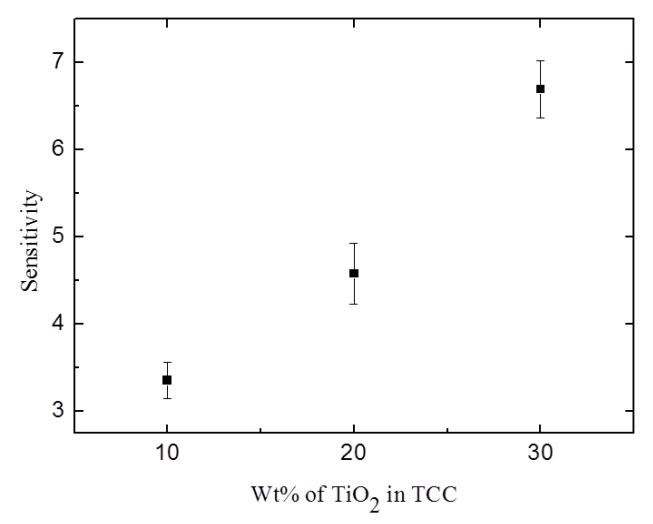

(b)

Fig. 6. (Color online) (a) I- $V$ characteristics and (b) sensitivity of TCC urea biosensor depending on weight ratio of $\mathrm{TiO}_{2}$. 
shows the $I-V$ characteristics of the TCC urea biosensor depending on the $\mathrm{TiO}_{2}$ weight percent value. The current increases with increasing weight ratio of $\mathrm{TiO}_{2}$. For instance, the current obtained at $2 \mathrm{~V}$ is $4.1 \mu \mathrm{A}$ for the sample of $10 \mathrm{wt} \% \mathrm{TiO}_{2}$, and the current increases with increasing $\mathrm{TiO}_{2}$ weight percent value. The current values obtained for the samples of 20 and $30 \mathrm{wt} \% \mathrm{TiO}_{2}$ are 5.2 and $7.2 \mu \mathrm{A}$, respectively. Figure 6(b) shows the variations in sensitivity with different weight percent values of $\mathrm{TiO}_{2}$.

The sensitivity increased from 3.4 to 6.6 as the $\mathrm{TiO}_{2}$ weight percent increased from 10 to 30. A high $\mathrm{TiO}_{2}$ weight percent of the TCC shows increased electrical current and sensitivity, which is associated with the increased enzyme activity. The enhanced enzyme activity might be due to the increased loading capacity of the enzyme associated with $\mathrm{TiO}_{2}$ nanoparticles added into the TCC. The TCC prepared with $30 \mathrm{wt} \% \mathrm{TiO}_{2}$ was used for the urea biosensor since the largest current was observed.

\subsection{Effect of urea concentration}

Urea concentration plays a significant role in the determination of the enzyme activity of a urea biosensor. The sensing behavior of the urea biosensor was studied by changing the urea concentration. The calibration curve was plotted by considering the sensitivity as a function of urea concentration as shown in Fig. 7(a). Figure 7(b) shows a zoom-in plot at a low urea concentration.

The sensitivity increased with increasing urea concentration. The calibration curve shows three regions: (i) a highly sensitive region at a concentration lower than $10 \mathrm{mM}$, (ii) a transition region up to $50 \mathrm{mM}$, and (iii) a saturated region above $50 \mathrm{mM}$. The first region is the most sensitive region for urea detection. The proposed urea biosensor can be useful at concentrations lower than $10 \mathrm{mM}$. The transition region might be used to sense higher concentrations of urea. The third region is the saturation region. The unavailability of free urease sites for urea adsorption might form the saturation region

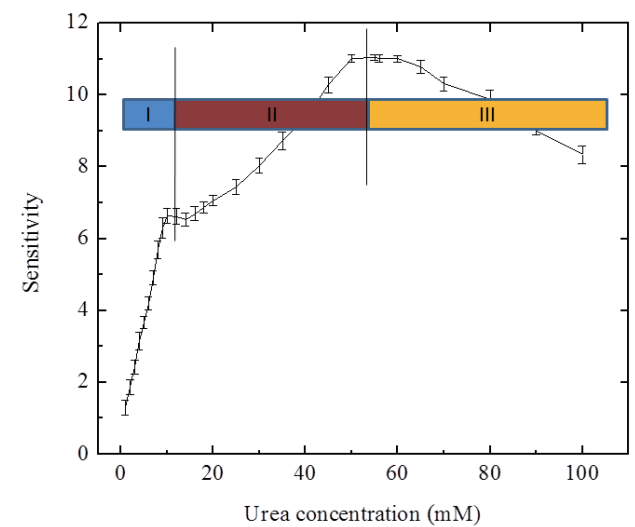

(a)

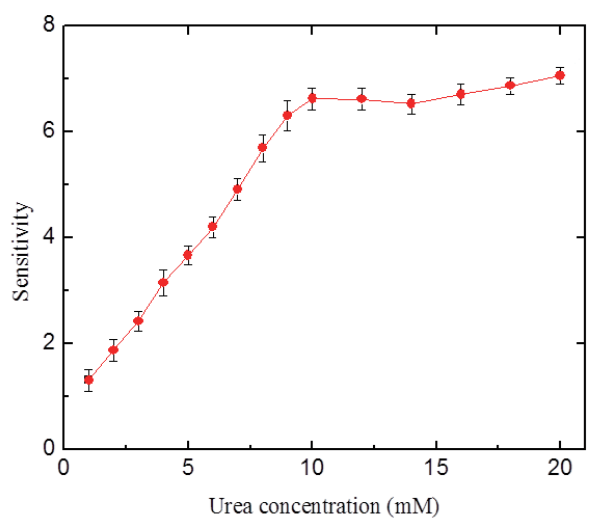

(b)

Fig. 7. (Color online) Sensitivity curves of TCC urea biosensor: (a) in wide range of urea concentrations and (b) at lower urea concentrations. 
at higher urea concentrations. The presence of three regions shows that the surface reactions are not the same at different urea concentrations. Physisorption would play a major role at lower concentrations, whereas chemisorption would be dominant at higher concentrations, resulting in the saturation of the biosensor performance. ${ }^{(19)}$

The performance of urea biosensors was compared with those of other biosensors fabricated on different polymer matrices (Table 1). When compared with other polymerbased urea biosensors reported, our proposed urea biosensor shows a detection range wider than $100 \mathrm{mM}$, which is wider than previous results. ${ }^{(15,16,20)}$ This improvement in the detection range may be attributed to the higher ability of $\mathrm{TiO}_{2}$ in the TCC to absorb more enzyme urease. To examine the stability of the proposed biosensor, repeated measurement was performed after storing the biosensor for different times under ambient condition in buffer solution ( $\mathrm{pH}$ 7.2). The sensitivity of the biosensor was stable after storing the biosensor for $96 \mathrm{~h}$, which proves the reliability of the biosensor. Since our urea sensor is made of cellulose, the TCC urea biosensor can be disposable.

\subsection{Detection mechanism of urea}

The microscopic model for a metal-oxide-based toxic gas sensor was first introduced by Windischmann and Mark. ${ }^{(20)}$ The physical basis of their model was the oxidation of the toxic gas by chemisorbed oxygen on the sensor and subsequent release of an electron from chemisorbed species to the conduction band of the sensor. Various reports based on this model since then have explained the variation in the electrical conductance of a highly porous semiconducting thick or thin film sensor in the presence of toxic gases due to the reactions occurring on the surface. ${ }^{(21)}$

For a urea detection mechanism, a similar explanation can be made. Atmospheric oxygen molecules are physisorbed on the surface sites of TCC. The oxygen molecules are then ionized by taking electrons from the conduction of $\mathrm{TiO}_{2}$ while moving from site to site and are consequently adsorbed on the surface of $\mathrm{TCC}$ as $\mathrm{O}^{-}{ }_{\text {ads. }}$. This reduces the conductance of the TCC through an increase in the potential barrier at the grain boundaries.

Table 1

Comparison of TCC urea sensor with polymer-based urea biosensors.

\begin{tabular}{lcccc}
\hline Matrix & $\begin{array}{c}\text { Urease immobilization } \\
\text { method }\end{array}$ & Transducer type & Linear range & Ref. \\
\hline $\begin{array}{l}\text { Polypyrrole and polyion } \\
\text { complex }\end{array}$ & Covalent bonding & Potentiometric & $30-300 \mathrm{mM}$ & 12 \\
$\begin{array}{c}\text { Polyaniline-poly }(n \text {-butyl } \\
\text { methacrylate) }\end{array}$ & Adsorption & Conductometric & $20-120 \mathrm{mg} / \mathrm{dl}$ & 13 \\
$\begin{array}{l}\text { Poly(vunyl ferrocenuim) } \\
\text { PVC-COOH polymer }\end{array}$ & Ionic bonding & Amperometric & $1-25 \mathrm{mM}$ & 15 \\
$\begin{array}{l}\text { Tin oxide thin film } \\
\text { TiO }{ }_{2} \text {-cellulose hybrid } \\
\text { nanocomposite }\end{array}$ & Adsorption & Conductometric & $1-50 \mathrm{mM}$ & 20 \\
\hline
\end{tabular}




$$
\mathrm{O}_{2}+2 \mathrm{e}^{-} \rightarrow \mathrm{O}^{-} \text {ads }
$$

When the urease-immobilized TCC is exposed to urea solution, the catalytic reaction of urease and urea occurs as

$$
\mathrm{NH}_{2} \mathrm{CONH}_{2}+2 \mathrm{H}_{2} \mathrm{O} \rightarrow 2 \mathrm{NH}_{4}^{+}+\mathrm{CO}_{3}^{2-} \text {. }
$$

This $\mathrm{NH}_{4}^{+}$ion reacts with surface-adsorbed oxygen $\left(\mathrm{O}^{-}\right.$ads $)$and further releases the trapped electron to the conduction band of $\mathrm{TiO}_{2}$ by the decrease in potential barrier at the grain boundary. Thus, the trapped electrons are returned to the conduction band of $\mathrm{TiO}_{2}$. The energy released during the decomposition of adsorbed ammonia molecules would be sufficient for letting the electrons jump to the conduction band causing an increase in the conductivity of the biosensor. ${ }^{(22)}$

\section{Conclusions}

A $\mathrm{TiO}_{2}$-cellulose composite was fabricated and its urea detection behavior was investigated. The TCC was prepared by blending $\mathrm{TiO}_{2}$ nanoparticles and cellulose solution with various weight percent values of $\mathrm{TiO}_{2}$. Enzyme urease was immobilized into the TCC by physical adsorption. The current of the urea biosensor increased with increasing weight percent value of $\mathrm{TiO}_{2}$ in the TCC. This increase in current was attributed to the surface morphology and increased $\mathrm{TiO}_{2}$ nanoparticles in the TCC. A urease-immobilized TCC was found to be highly sensitive to the urea concentration below $10 \mathrm{mM}$. The linear response obtained with the TCC covers a wide range of urea concentrations, which makes the TCC a potential candidate for an inexpensive, flexible, and disposable green biosensor.

\section{Acknowledgements}

This research was supported by the National Research Foundation of Korea (NRF2013M3C1A3059586).

\section{References}

1 J. Zhou, S. Liu, J. Qi and L. Zhang: J. Appl. Polym. Sci. 101 (2006) 3600.

2 J. Kim, S. Yun and Z. Ounaies: Macromolecules 39 (2006) 4202.

3 J. Schurz: Prog. Polym. Sci. 24 (1999) 481.

4 P. A. A. P. Marques, T. Trindade and C. P. Neto: Compos. Sci. Technol. 66 (2006) 1038.

5 D. Mumalo-Djokic, W. B. Stern and A. Taubert: Cryst. Growth Des. 8 (2007) 330.

6 R. J. B. Pinto, P. A. A. P. Marques, A. M. Barros-Timmons, T. Trindade and C. P. Neto: Compos. Sci. Technol. 68 (2008) 1088.

7 S. Yabuki, M. Iwamoto and Y. Hirata: Materials 7 (2014) 899.

8 E. W. McFarland and J. Tang: Nature 421 (2003) 616.

9 H. Miyazakia, T. Hyodob, Y. Shimizua and M. Egashira: Sens. Actuators, B 108 (2005) 467.

10 P. Yu, K. Zhu, A. G. Norman, S. Ferrere, A. J. Frank and A. J. Nozik: J. Phys. Chem. B 110 (2006) 25451. 
11 M. Singh, N. Verma, A. K. Garg and N. Redhu: Sens. Actuators, B 134 (2008) 345.

12 T. Osaka, S. Komaba, M. Seyama and K. Tanabe: Sens. Actuators, B 36 (1996) 463.

13 S. M. U. Alia, Z. H. Ibupotoa, S. Salmanb, O. Nura, M. Willandera and B. Danielsson: Sens. Actuators, B 160 (2011) 637.

14 B. Kovácsa, G. Nagya, R. Dombib and K. Tóthc: Biosens. Bioelectron. 18 (2003) 111.

15 P. Rolfe: Sens. Mater. 24 (2012) 275.

16 M. Gutiérrez, S. Alegret and M. D. Valle: Biosens. Bioelectron. 22 (2007) 2171.

17 M. Maniruzzaman, S. D. Jang and J. Kim: Mater. Sci. \& Eng. B 177 (2012) 844.

18 S. Yun, J. Kim and S. K. Lee: Int. J. Precis. Eng. Manuf. 11 (2010) 987.

19 S. K. Mahadeva and J. Kim: Sens. Actuators, B 157 (2011) 177.

20 H. Windischmann and P. A. Mark: J. Electrochem. Soc. 126 (1979) 627.

21 S. G. Ansari, Z. A. Ansari, R. Wahab, Y. S. Kim, G. Khang and H. S. Shin: Biosens. Bioelectron. 23 (2008) 1838.

22 S. G. Ansari, Z. A. Ansari, H. K. Seo, G. S. Kim, Y. S. Kim, G. Khang and H. S. Shin: Sens. Actuators, B 132 (2008) 265. 